be the loser. Even in France medical men are by no means agreed as to the use to be made of the treatment. Dr. Liebeault, of Nancy, seems to have given himself up to hypnotising as if it were the only resource of the medical art. The distinguished Charcot, on the other hand, considers that only hysterical persons can or ought to be hypnotised. The indiscriminate use of such a peculiar method of treatment he warmly condemns. Dr. Lloyd Tuckey, in this country, we believe, still practises hypnotically, and probably a limited number of other persons. The present state of the British medical judgment is perhaps this : that the phenomena of hypnotism are undoubtedly real and not to be denied; that certain hysterical persons of both sexes may be treated hypnotically with present advantage, and possibly without future injury; but that hypnotism is no more to be practised, except in cases of extreme necessity, than is chloralism, morphinism, or any other method of treatment of which the disadvantages are almost as great as the benefits. We congratulate ourselves and our fellow-countrymen that our nerves are as yet so firm and steady that hypnotism is but a curiosity amongst us. Long may it remain so !

\section{PASTEUR AND HYDROPHOBIA.}

In the spring of the year Sir Henry Roscoe, at the Sunday Lecture Society, undertook to expound and defend Pasteur's inoculation treatment for hydrophobia. The expounder did not give an exposition, and the defender failed to defend. An able indictment of Pasteurism has been drawn up by Dr. Dolan, of Halifax, to which no competent reply is as yet forthcoming. Several writers in THE HoSPITAL have pointed out the a priori physiological difficulties which beset the method of Pasteur. No attempt of any importance has been made to meet these contentions. The position which this journal has taken up on the subject, and which it still holds, is this: That the a priori physiological difficulties in the way of Pasteur's antirabic treatment are exceedingly great; and that if the argument from analogy alone were held to be conclusive those difficulties would be insurmount. able; but that, analogy notwithstanding, if undoubted facts and reliable statistics can be shown on the side of Pasteur, we shall bow to the actual and discard the a priori as misleading in the present instance. Pasteurism is still sub judice, and will probably long remain so. Those who value truth and a scientific reputation more than consistency will do well to recognise this fact.

\section{MR. GLADSTONE : SIR GEORGE STOKES.}

Two very eminent persons outside the medical profession made incursions into regions which, though not both medical, yet have a profound interest for physicians and pure physiologists. Mr. Gladstone visited Guy's Hospital and formally opened the Students' House. In an audience bristling with medical persons of all sorts, he frankly confessed that he himself had practised unlicensed medical treatment, and that it had been singularly: successful. Wielding his woodman's axe one day in the dim and trackless forest of Hawarden, he had the misfortune to inflict upon himself a somewhat severe wound. The blood flowed freely; and, as neither Sir Andrew Clark nor the Hawarden Asculapius was immediately available, Mr. Gladstone applied some of the leaves of a neighbouring tree to the staunching of the wound, and with immediate success. The audience assembled at Guy's did not consult the solicitor of the Medical Defence Association. The unlicensed practitioner was permitted to escape for that time. Sir George Stokes, the distinguished president of the Royal Society, appealed to the profoundest imaginations and the grandest hopes of practically all the members of the human race when he expressed his belief in the possibility of a future life. This is not the place to give even an outline of his argument. But that so distinguished a representative of all that is profoundest and best in the science of the times should have announced his belief in such a possibility is not only an encouragement to the philosophical moralist, but a distinct indication that the reign of the "scientific mechanic" is coming to an end, and that science herself will soon become as philosophical, and as full of poetry and life as she has recently been wooden and cramped and dead.

\section{BLACK CLOUDS OVER HOSPITALS.}

If Zadkiel had cast the horoscope of the hospitals at the beginning of last year he would have announced "thunderclouds, wars, prodigies, and portents"' Never was there a year within our recollection when hospitals were so investigated, cross-examined, suspicioned, to coin a word, and criticised as they have been during the past twelve months. The Lords' Committee was welcomed by hospital managers, because they felt sure that it would prove a vindicator of their work, and give a fresh impulse to all their activities. It has not proved anything as yet, except its incapacity for distinguishing between essentials and accidentals, and its keen love of the minute female gossip which constitutes the staple of conversation at afternoon teas. Whether such an appetite for gossip is consistent with a Lords' Committee we must leave the lords themselves to decide. They have still much ground to cover, and we must hope that in their future proceedings a properly judicial temper will not be wanting. The London Hospital and its matron have been put into the fire; or shall we say into the lion's den? They have come out again, like certain famous patriots of old, with " not a bone broken, nor a hair of their head singed." It is passing strange, but a happy encouragement to well-doing, that, notwithstanding the gauntlet which the hospitals have had to run during the year, their public benefactions should have reached a higher level than they have ever attained before. The Hospital Sunday Fund amounted to nearly $£ 42,000$, and was more than $£ 1,000$ in excess of any previous series of collections. In the Saturday Fund the proportionate increase was decidedly greater still. In spite, however, of these encouraging facts, there was an excess of $£ 75,000$ in expenditure as compared with income in the Metropolitan hospitals alone. The total income of those hospitals from all sources was £396,789; the expenditure was $£ 571,583$. On behalf of the Sunday Fund, the usual annual meeting was held at the Mansion House, and Mr. Jonathan Hutchinson, F.R.S., President of the Royal College of Surgeons, delivered an address full of originality, power, and sound argument. That address was a complete vindication of the aims and work of the voluntary hospitals of Great Britain.

\section{THE DEAD.}

Space warns us to be brief in our further references to public events. But we cannot forbear calling to recollection the loss which the public and the medical profession sustained during the year by the death of Dr. Matthews Duncan and several other well-known medical practitioners. Dr. Matthews Duncan was hardly an aged man, as medical men are called aged. Both as a physician and as a man he was earnest, honest, and capable; and he had his reward in the confidence of his brethren and the admiring affection of a large and discriminating section of the public. Towards the close of the year also died Lady Rosebery, still comparatively in her youth. She was a doer of good deeds and a friend of those that did them; she was officially connected with the National Pension Fund for Nurses, and a warm supporter of hospitals and deserving charitable institutions. The world of charity is made poorer by Lady Rosebery's death, and all good people who knew her mourn her loss.

\section{KOCH AND THE CONSUMPTION CURE}

(4) The event of 1890 which caused the greatest excitement in the medical world, and perhaps in the world generally; was 